\title{
Cost-effectiveness analysis of six therapies for the treatment of lower urinary tract symptoms due to benign prostatic hyperplasia
}

This article was published in the following Dove Press journal:

ClinicoEconomics and Outcomes Research

\author{
James C Ulchaker' \\ Melissa S Martinson ${ }^{2}$ \\ 'Department of Urology, Cleveland \\ Clinic, Cleveland, $\mathrm{OH},{ }^{2} \mathrm{Technomics}$ \\ Research, LLC, Minneapolis, MN, USA
}

Objective: To conduct a cost-effectiveness analysis from payers' perspectives of six treatments for lower urinary tract symptoms (LUTS) associated with benign prostatic hyperplasia (BPH) and to examine positioning of these modalities in the marketplace for the best use of health care funds and quality-of-life benefits for patients.

Methods: The economic analysis was conducted with a Markov model to compare combination prescription drug therapy (ComboRx), minimally invasive therapies (MITs) including convective radiofrequency $(\mathrm{RF})$ water vapor thermal therapy $\left(\operatorname{Rezūm}^{\circledR}\right)$, conductive RF thermal therapy $\left(\right.$ Prostiva $\left.^{\circledR}\right)$, and prostatic urethral lift $\left(\mathrm{UroLift}^{\circledR}\right)$, and invasive surgical procedures including photovaporization of the prostate (Greenlight $\left.{ }^{\mathbb{R}} \mathrm{PVP}\right)$ and transurethral resection of the prostate (TURP). Effects assessed with International Prostate Symptom Score, adverse events, and retreatment rates were estimated from medical literature; treatments effects were modeled using a common baseline score. Starting with each therapy, patients' transitions to more intensive therapies when symptoms returned were simulated in 6-month cycles over 2 years. Incremental cost-effectiveness ratios (ICERs) were calculated for pairs of treatments; uncertainty in ICERs was estimated with probabilistic sensitivity analyses.

Results: ComboRx was least effective and provided one-third of the symptom relief achieved with MITs. UroLift was similar in effectiveness to Prostiva and Rezūm but costs more than twice as much. The cheaper MITs were $\sim \$ 900$ more expensive than the cost of ComboRx generic drugs over 2 years. TURP and PVP provided slightly greater relief of LUTS than MITs at approximately twice the cost over 2 years; typically, they are reserved for treatment of more severe LUTS.

Conclusion: The analysis evaluated the costs and symptom relief of six treatment options in the continuum of care from a common baseline of LUTS severity. Identification of treatments for LUTS/BPH that demonstrate cost-effectiveness and provide appreciable symptom relief is paramount as reimbursement for patient care moves from volume-based services to valuebased services.

Keywords: prostate, benign prostatic hyperplasia, lower urinary tract symptoms, costeffectiveness analysis, minimally invasive therapy

\section{Introduction}

Benign prostatic hyperplasia (BPH) is very common with aging. It is a chronic condition often associated with a progressive development of voiding and obstructive lower urinary tract symptoms (LUTS). Nearly a third of all men develop LUTS, primarily from $\mathrm{BPH}$; thus, due to high health care costs, $\mathrm{BPH}$ is included in the top ten prominent and costly diseases in men over 50 years of age in the US. ${ }^{1}$ The prevalence of LUTS/BPH, its impact on patients and their partners, and societal costs of this condition have been
Correspondence: James C Ulchaker Department of Urology, Cleveland Clinic, 9500 Euclid Avenue, Cleveland, $\mathrm{OH}$ 44195, USA

$\mathrm{Tel}+\mathrm{I} 2164451786$

Fax + I 2166364492

Email ulchakj@ccf.org 
well described..$^{2-4}$ While men less than 30 years of age have little evidence of BPH histology, the prevalence increases with each decade. BPH occurs in 50\% of men 50-60 years of age, and in $90 \%$ of those older than 80 years. ${ }^{5,6}$ When LUTS become sufficiently bothersome and affect quality of life, men seek care from primary care physicians and urologists. Mild LUTS are typically managed with watchful waiting followed by drug therapy as the first line of treatment. ${ }^{7}$ The prevalence and progression of symptoms increase with advancing age, ${ }^{8,9}$ thereby necessitating consideration of alternative therapeutic modalities.

A 2015 population study estimates that 35.5 million men of age more than 30 years and 33.9 million men of age 40-79 years have at least mild urinary tract symptoms. Some studies indicate that only about a third of men with bothersome LUTS are aware of pharmacological agents or surgical interventions available to treat their condition. Even so, in 2015 , it was estimated that 12.2 million men were actively managed for LUTS/BPH; this accounts for one of the largest segments of almost $25 \%$ of a urology practice. ${ }^{10,11}$ A decade ago, annual direct and indirect costs to the private sector related to BPH treatment in the US were estimated at $\$ 4$ billion. ${ }^{12}$ The costs begin to accrue with men in their fourth decade as BPH is not only a disease of older men.

A perceptible change occurred in the management of LUTS/BPH after pharmacological agents became available. There was a significant decrease in the number of BPH surgical procedures. However, drug adherence rates are often low and may vary with class of drugs used. ${ }^{13,14}$ Lack of compliance is attributed to drug side effects, including sexual dysfunction, and lower-than-perceived expectations in the degree of improvement in symptoms and quality of life. ${ }^{14,15}$ Although patients may be prepared to wait longer periods of time for symptom relief with drugs in order to avoid surgery, drugs are expensive over long periods of time. ${ }^{16,17}$ Furthermore, compliance in some older patients is problematic. Men do not want to commit to lifetime drug therapy, often requiring multiple drugs for their chronic LUTS/BPH. The emergence of minimally invasive $\mathrm{BPH}$ treatments allows clinicians to tailor therapies in a continuum between medical management and more invasive surgical approaches as the condition progresses in severity.

The economic impact of treatment for BPH symptoms will continue to increase commensurate with the aging population. A report from the Centers for Disease Control and Prevention estimates that $20 \%$ of the population will be 65 years of age or older by 2030 and those 85 years and older will be the fastest growing segment of our population. ${ }^{18}$
While there are multiple options for treating BPH including medical, surgical, and newer minimally invasive therapies (MITs), the challenge related to costs to our society revolves around when to initiate, substitute, and/or advance to a more prostate tissue-targeted therapy after worsening of LUTS to achieve the best outcomes for patients. The purpose of this cost-effectiveness analysis is to examine critical positioning of treatments for LUTS/BPH in the marketplace and the best use of health care funds and quality-of-life benefits for the patient in the US.

The analysis estimated costs and effects of six therapies; the selected therapies are among those recommended in the American Urological Association (AUA) and European Association of Urology guidelines for the management of BPH. ${ }^{7,19}$ The National Institute of Diabetes and Digestive and Kidney Diseases subsequently convened a panel of key opinion leaders to develop a comprehensive strategic plan for advancing research in benign prostate disease including further development of intervention therapies based on nonor minimally invasive approaches. ${ }^{20}$

\section{Methods}

\section{Model-based cost comparison using clinical outcomes}

The economic model was structured using a Markov model programmed in TreeAge Pro 2016 (TreeAge Software, Inc.) as shown in Figure 1. Simulated patients started with a therapy and transitioned between follow-up and re-treatment if symptoms returned, in cycles with a length of 6 months. The base-case timeframe of 2 years was selected to encompass the limited posttreatment follow-up times of 2 years for some of the MITs included in the analysis. The authors acknowledge that longer-term results are important to all stakeholders, but for most BPH therapies, the short-term trends have been consistent with longer-term results.

The six therapies included:

- Therapy with combination prescription drugs ("ComboRx"), an inhibitor of $5 \alpha$-reductase (e.g., dutasteride or finasteride), and an $\alpha$-selective adrenergic receptor blocker (e.g., tamsulosin or doxazosin)

- The MITs of the following:

- The Rezūm ${ }^{\circledR}$ System (a radiofrequency [RF] thermal therapy procedure)

- The Prostiva ${ }^{\circledR}$ RF Therapy System (an RF thermal therapy procedure)

- The UroLift ${ }^{\circledR}$ System (prostatic urethral lift, permanent implants to retract enlarged prostate tissue) 


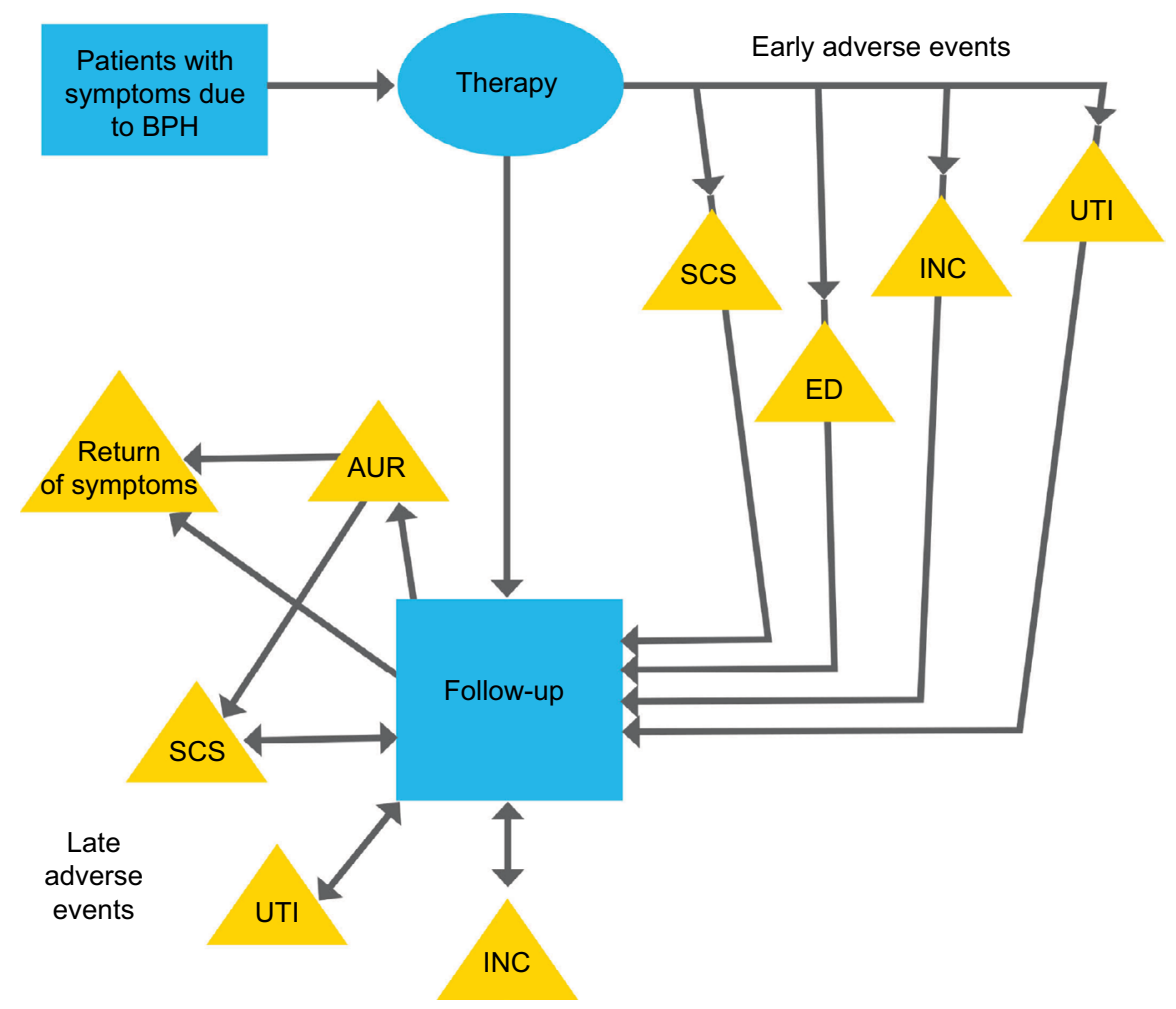

Figure I Model for LUTS due to BPH.

Abbreviations: AUR, acute urinary retention; BPH, benign prostatic hyperplasia; ED, erectile dysfunction; INC, incontinence; LUTS, lower urinary tract symptoms; SCS, stricture, contracture, or stenosis; UTI, urinary tract infection.

- The invasive therapies of the following:

- Greenlight ${ }^{\circledR}$ laser photovaporization of the prostate (PVP)

- Transurethral resection of the prostate (TURP)

The simulated patients start with one of the treatments. Following treatment, the patients move through the model in 6-month cycles in which they could experience an adverse event (AE) requiring treatment, or return of significant $\mathrm{BPH}$ symptoms for which they would receive an additional therapy, or their experience could be uneventful, in which case they would incur only routine follow-up costs.

Common early- and late-occurring AEs whose treatment costs are significant were included in the model. Early AEs occurring within 6 months after treatment included: incontinence; de novo erectile dysfunction (ED), and stress/urge incontinence that is not self-resolving, urethral strictures, bladder neck contractures or stenosis, and urinary tract infections (UTIs). The non-resolving ED and some incontinence were assumed to be permanent and need chronic therapy. The late AEs, occurring 6 months or later after treatment, included acute urinary retention (AUR), incontinence, strictures, contractures, or stenosis, and UTIs. AUR was assumed to be due to either disease progression or a stenosis and treated accordingly.

In the model, when a patient's symptoms return, the patient may be treated with a more invasive therapy in the following cycle. The treatment with increasingly more invasive therapies is intended to represent a continuum of care. For example, patients who initially received ComboRx and then have inadequate relief are treated with one of the three designated MITs (Rezūm, Prostiva, or UroLift) randomly chosen by the model in equal proportions. Afterward, they are modeled as MIT patients with regard to AEs and return of symptoms. Those patients who initially received an MIT and experience symptoms recurrence are retreated once with the same MIT, but then advance to an invasive surgical procedure (PVP or TURP, again randomly chosen by the model in equal proportions) when and if symptoms return a second time; afterward, they are modeled as invasive therapy/surgical patients. Patients who initially received PVP are treated with a second PVP; however with symptom progression, they advance to a TURP. Once a patient has a TURP, when additional treatment is required, another resection is performed. There is no mortality in the model because of the short time horizons analyzed. 
We modeled the movement from less invasive to more invasive therapies because we wanted to understand if this overall strategy made sense clinically and financially. The cost of combination drugs (generic) over a year or 2 is lower than the cost of both RF thermal therapy procedures, which is lower than that of either invasive therapy procedure. Nonetheless, it is possible for AEs and repeated procedures to overwhelm up-front cost savings. To understand the total costs, we structured the model such that patients getting maximum medical therapy whose symptoms return get an MIT, and patients who have had MIT but whose symptoms return get a redo MIT procedure and then move on to an invasive procedure.

The model accumulates costs associated with each type of BPH therapy and treatments of AEs. Costs are derived from 2016 Medicare national average fee schedules for the BPH therapies including drugs, diagnostics, and procedures, and treatments for the AEs. References that contributed data on the frequency of revision procedures/treatments (re-treatment with same method or alternative treatment) or return of symptoms were used to calculate costs by using the timediscounted Medicare reimbursements as the cost each time a revision procedure occurred in the model. An analogous method was used for AEs and diagnostics. Drug payments were estimated from the 2014 Medicare Part D prescriber data for the combination drug therapy. For other drugs, such as those used in the treatment of incontinence, the Federal Upper Limit payments for 2016 set by the Affordable Care Act were used. Treatments for AEs included diagnostics, procedures, and drugs based on the advice of an advisory panel of three physicians: one advisor from an academic clinical practice and two advisors serving as medical directors in large health plans. Alternative treatments for a specific AE are weighted by their relative frequencies from the 2014 Medicare MEDPAR counts of procedures. ${ }^{21}$

\section{Literature search methodology for data sources}

To identify relevant citations, the PubMed (http://www.ncbi. nlm.nih.gov/pubmed/) database was searched for references in the English language from 2001 to June 2017. The search strategy included the Medical Subject Headings (MeSH) for the following: "Prostatic Hyperplasia" (MeSH) AND Benign or $\mathrm{BPH}$, and each of the selected therapies ("combination drug therapy" or "polytherapy"; "prostatic urethral lift" or "UroLift"; "transurethral needle ablation" [TUNA, limited to Prostiva or Rezūm] or "Prostiva" [a transurethral, conductively delivered RF heat therapy] or "Rezūm" [a transurethral, convectively delivered RF water vapor thermal therapy]; "photovaporization of the prostate" or PVP [limited to Greenlight] or "Greenlight"; "transurethral resection of the prostate" or "TURP"). The search included primary research studies or case series published in peer-reviewed journals. Reviews and reports of single cases were excluded. Of the potentially relevant citations, 40 articles were selected and used to source data for this assessment.

The effectiveness of treatment was evaluated with the International Prostate Symptom Score (IPSS), a validated questionnaire for evaluating LUTS associated with BPH. The IPSS questionnaire is self-administered by the patient, comprising seven symptom questions (feeling of incomplete bladder emptying, frequency, intermittency, urgency, weak stream, straining, and nocturia, each referring to during the last month) and a quality-of-life item. Scores range from 0 (no symptoms) to 35 (most severe); a score of 8-19 indicates moderate LUTS, and 20-35 severe LUTS. The instrument is used to screen for, rapidly diagnose, and track the symptoms of, and suggest management of the LUTS due to BPH. The IPSS questionnaire is a standard instrument to assess treatment outcomes relative to baseline in most clinical trials.

\section{Analytical procedures}

Because the baseline IPSSs tended to be lower in patients treated with drugs than with procedures, the effectiveness of each treatment was estimated by calculating the weighted average annual change in IPSS relative to the baseline in the reference. Then, all patients were assigned the same baseline score in the model (IPSS of 22) to make the comparisons among therapies as fair as possible. The standard deviation (SD) of means from individual studies was used in the probabilistic sensitivity analysis.

The rate of early AEs was estimated by calculating weighted averages of the rates for 3 or 6 months as available. The rate of late AEs was estimated similarly at annual intervals and averaged over 1-2 years. The SD of rates of early and late AEs was used in the probabilistic sensitivity analysis.

Costs and cost-effectiveness were analyzed over 2 years from the perspective of the health care payer. Uncertainty was evaluated using a probabilistic sensitivity analysis in which IPSSs used normal distributions and rates per cycle used beta-binomial distributions. Each variable in the model was represented by values randomly chosen from the respective probability distribution. Costs and effects were discounted at $3 \%$.

Cost-effectiveness was estimated by an incremental costeffectiveness ratio (ICER) comparing two treatments at a 
time. It is calculated using the difference in the average costs of each pair of treatments divided by the difference in their average effects (i.e., IPSS change from baseline with treatment A minus IPSS change from baseline with treatment B). In this study, the ICER represents the cost of each additional point decrease in the IPSS achieved by the more effective treatment (an IPSS decrease represents an improvement). If a treatment is both more effective and less costly when compared to another, it is defined as dominant to the other.

A probabilistic sensitivity analysis is intended to include most or all of the uncertainty about the parameters and the samples; thus, a traditional sensitivity analysis in which one or two parameters are varied at a time is unnecessary. The probabilistic sensitivity analysis in this study was run with 1,000 samples of the parameters and 100 individuals within each sample for a total of 100,000 simulations. Estimates of costs, effects, and ICERs were calculated using a probabilistic sensitivity analysis and graphed on the cost-effectiveness plane and in cost-effectiveness acceptability curves (CEACs).

\section{Results}

\section{Estimates of effectiveness of treatments in cost-effectiveness analysis}

Data were obtained from the literature to support a 2-year cost-effectiveness analysis. Weighted means were calculated from IPSSs, AE rates, and re-treatment rates reported in the papers. Estimates of effectiveness of each treatment (IPSS change), re-treatment rates, and probabilities of the occurrence of early and late AEs are shown for the six therapeutic modalities in Table 1.

The three MIT options resulted in similar degrees of relief of LUTS; in each, the mean IPSS decreased (improved) about 11 points at year 1 and were sustained at year 2 . However, the UroLift procedure patients had a fivefold or greater rate of return of symptoms through year 2 (Table 1). The re-treatment rates for all treatments were estimated by the same methods: reported rates or number of events in the references were converted to a best-estimate time-to-event rate for each time period. Then, the rates were averaged over a 2-year period. This method assumes that the rate over 2 years is approximately constant.

The more invasive surgical options (Greenlight PVP and TURP) provided the greatest symptom relief; IPSS decreased a mean of nearly 16 points for both therapies at year 1, but relief diminished slightly to a 13-point reduction at year 2. Treatment with ComboRx resulted in appreciably less symptom relief over 2 years, and these patients had the highest rate (5.4\%) of de novo ED. Greenlight PVP- and
TURP-treated patients experienced a higher incidence of incontinence, stricture, contracture, or stenosis, and UTI than other modalities. The service components and fee schedules of the six therapies and treatment of AEs are shown in Table 2.

\section{ICERs}

The ICERs comparing pairs of therapies discounted at 3\% over 2 years are shown in Table 3 . The baseline IPSS of 22 was used for comparison of the therapies. Drug therapy, including ComboRx, is recommended as the first line of treatment for bothersome LUTS/BPH by AUA management guidelines. The generic ComboRx is the least expensive therapy but also the least effective. The branded ComboRx is the most expensive of all treatment options but has a similar low-effectiveness result as generic ComboRx.

At 2 years, after commencing ComboRx (generic or branded) treatment, the mean IPSS was about 19 , only a 3-point improvement in symptom score, defined as a minimal but meaningful improvement. The two RF energy-generated thermal therapies, Prostiva and Rezūm, were similar; they were intermediate in costs and effects when compared to Greenlight PVP and TURP, which were very similar. Prostiva and Rezūm treatments reduced IPSS by 11 or 12 points compared to baseline. These IPSS reductions were about 25\% less than TURP (16-point IPSS reduction); however, the ICERs were considerably higher for TURP and Greenlight PVP. The cost per additional point reduction in IPSS was $\$ 97$ for Rezūm versus generic ComboRx and \$686 for TURP versus Rezūm.

\section{Cost-effectiveness simulations (ICERs) and probabilistic sensitivity analysis}

The simulated ICERs for ComboRx, MITs, and invasive therapies are presented in Figure 2. These simulations include the probabilistic sensitivity analysis, so they include the uncertainty in the estimates of effects and rates. (The CEACs in Figure 3 summarize these probabilistic sensitivity analysis results.) The horizontal axis in the figures represents the difference in cost between two therapies, and the vertical axis the difference in effectiveness. When a fair proportion of simulated costs and effects are on both sides of the effectiveness-difference axis or the cost-difference axis, evidence for a meaningful difference between the treatments is weak. A comparison of the two RF thermal therapies, Rezūm and Prostiva, shows Rezūm to be slightly more expensive about $66 \%$ of the time and more effective about $97 \%$ of the time, indicating that the costs are unlikely to differ much, but offering strong evidence of a point difference in effectiveness 
Table I Estimates of effectiveness of treatment (IPSS improvements), durability of effects, and transition probabilities ${ }^{\text {a }}$ for occurrence of early and late AEs

\begin{tabular}{|c|c|c|c|c|c|c|c|c|c|}
\hline \multicolumn{4}{|c|}{$\begin{array}{l}\text { Number of subjects included in effectiveness } \\
\text { and safety assessments }\end{array}$} & \multicolumn{4}{|c|}{ Change in IPSS compared with baseline* } & \multicolumn{2}{|c|}{ Return of LUTS (\% patients) } \\
\hline & Baseline & Year I & Year 2 & & Year I & Year 2 & Reference & $\begin{array}{l}\text { Per 6-month } \\
\text { cycle }\end{array}$ & Reference \\
\hline ComboRx & 2,524 & 2,403 & $\mathrm{I}, 575$ & ComboRx & -1.70 & -6.20 & 22,23 & 0.70 & 23 \\
\hline Rezūm $^{\circledast}$ & 189 & 165 & 109 & Rezūm & -11.65 & -11.80 & $24-26$ & 0.60 & $24-26$ \\
\hline UroLift $^{\circledast}$ & 420 & 331 & 136 & UroLift & -10.65 & -9.47 & $27-33$ & 4.92 & $27-29$ \\
\hline Prostiva $^{\circledR}$ & 626 & 346 & 139 & Prostiva & -11.24 & -11.06 & $34-40$ & 0.93 & $34,37,38,41$ \\
\hline Greenlight $^{\circledast}$ PVP & 2,478 & $\mathrm{I}, 185$ & 432 & Greenlight PVP & -15.08 & -13.62 & $42-50$ & 0.93 & $42-46,48,49,5 I-54$ \\
\hline TURP & 539 & 429 & 302 & TURP & -16.79 & -13.06 & $\begin{array}{l}33,35,36,44- \\
46,49,54-58\end{array}$ & 0.31 & $44-46,49,58$ \\
\hline
\end{tabular}

AEs (\% patients) per 6-month cycle

\begin{tabular}{|c|c|c|c|c|c|c|c|c|c|c|c|c|c|}
\hline \multirow[b]{2}{*}{ Therapy } & \multicolumn{3}{|c|}{ Incontinence } & \multicolumn{2}{|c|}{$\begin{array}{l}\text { De novo erectile } \\
\text { dysfunction }\end{array}$} & \multicolumn{3}{|c|}{$\begin{array}{l}\text { Stricture, contracture, } \\
\text { or stenosis }\end{array}$} & \multicolumn{2}{|c|}{$\begin{array}{l}\text { Acute urinary } \\
\text { retention }\end{array}$} & \multicolumn{3}{|c|}{$\begin{array}{l}\text { Urinary tract } \\
\text { infection }\end{array}$} \\
\hline & Early ${ }^{\mathrm{b}}$ & Late $^{c}$ & Ref. & Early & Ref. & Early & Late & Ref. & $\begin{array}{l}\text { Through } \\
\text { Year } 2\end{array}$ & Ref. & Early & Late & Ref. \\
\hline ComboRx & 0.07 & 0.02 & 22 & 5.38 & 59 & $0.01^{d}$ & $0.01^{d}$ & NA & 0.07 & 22 & 0.07 & 0.02 & 22 \\
\hline Rezūm & $0.0 \mathrm{I}^{\mathrm{d}}$ & $0.0 \mathrm{I}^{\mathrm{d}}$ & $24-26$ & $0.01^{d}$ & $24-26$ & 1.13 & 0.42 & $24-26$ & 0.27 & $24-26$ & 1.99 & 0.43 & $24-26$ \\
\hline UroLift & 1.05 & 0.97 & $27-33$ & $0.01^{d}$ & $27-33$ & $0.01^{d}$ & $0.01^{d}$ & 33 & 1.31 & $26-33$ & 2.17 & 0.64 & $27-33$ \\
\hline Prostiva & $0.0 \mathrm{I}^{\mathrm{d}}$ & 0.26 & 39 & 0.46 & 36,39 & $0.01^{d}$ & 0.11 & $36-39$ & $0.01^{d}$ & NA & 4.77 & 1.59 & 39 \\
\hline Greenlight PVP & 4.75 & $0.0 \mathrm{I}^{\mathrm{d}}$ & $42,43,45,46,52$ & $0.01^{d}$ & $43,45,46,60$ & $1.5 \mathrm{I}$ & 0.61 & $43-51,53,54$ & 1.30 & $\begin{array}{l}43,50,51 \\
53,54\end{array}$ & $19.90^{\mathrm{e}}$ & I.II & $\begin{array}{l}44,46,50 \\
51,53,54\end{array}$ \\
\hline TURP & 2.06 & 0.78 & $50,51,54,58,61$ & 1.05 & 33,46 & 4.66 & 0.62 & $\begin{array}{l}46,49- \\
51,54,58,61\end{array}$ & 1.76 & $\begin{array}{l}33,50 \\
51,54\end{array}$ & $12.23^{e}$ & 2.09 & $\begin{array}{l}33,46,50 \\
51,54,61\end{array}$ \\
\hline
\end{tabular}

Notes: A decrease (minus sign) in IPSS represents an improvement compared with baseline. A common baseline IPSS of 22 was used for comparison of the treatment modalities in the model. For the modeling, it is assumed that ComboRx is the typical first line of treatment for LUTS/BPH. Patients who have inadequate symptom relief or worsening of LUTS may progress to one of the three MIT options ( 0.33 assumption). Patients who progress after an MIT have two surgical options ( 0.5 assumption). Early AEs are those occurring within 6 months after treatment, while late AEs are those occurring 6 months or later after treatment. ${ }^{\text {aPer }}$ 6-month cycle. ${ }^{\mathrm{b}}$ First 6-month cycle. 'After first 6-month cycle. ${ }^{\mathrm{W}} \mathrm{W}$ hen $\mathrm{AE}$ is not reported in any source, the rate is indicated as $0.0 \mathrm{I}$ for modeling purposes. ${ }^{\mathrm{e}}$ Early rates in the few papers with reports were very high. *From baseline reported in the individual papers.

Abbreviations: AE, adverse event; BPH, benign prostatic hyperplasia; ComboRx, combination prescription drug therapy; Greenlight PVP, photovaporization of the prostate; IPSS, International Prostate Symptom Score; LUTS, lower urinary tract symptoms; MIT, minimally invasive therapy; NA, not available; Prostiva, conductive radiofrequency thermal therapy; Ref., reference; Rezūm, convective radiofrequency water vapor thermal therapy; TURP, transurethral resection of the prostate; UroLift, prostatic urethral lift.

(Figure 2A). However, the average point difference is not clinically meaningful, as it is less than 3 points.

Figure 2B compares UroLift and Rezūm (UroLift compared to Prostiva was similar). The UroLift procedure costs about $\$ 3,500$ more than a Rezūm procedure on average. It is more expensive and less effective in $100 \%$ of the simulations; therefore, the Rezūm procedure dominates. Table 2 shows the service cost of approximately $\$ 6,400$ over 2 years for UroLift.

Figure $2 \mathrm{C}$ compares the invasive therapies, TURP and Greenlight PVP. TURP is more expensive about $59 \%$ of the time and more effective about $73 \%$ of the time, indicating that these therapies are likely to be similar. Both TURP and Greenlight PVP are more costly but also provide a slightly greater relief of LUTS compared with Rezūm; average IPSS decrease by 13 points for the invasive therapies versus almost 12 points for Rezūm at 2 years (Figure 2D and E). The Rezūm therapy is more costly than generic ComboRx (the branded ComboRx is, however, more expensive), but in both simulations Rezūm is more effective (Figure $2 \mathrm{~F}$ and $\mathrm{G}$ ). The elongation of values in both figures is indicative of the great variability in effectiveness for ComboRx (generic and branded). This variability reflects variations in patients' clinical condition, different responses and/or success of drug therapy to alleviate LUTS, and the significant lack of compliance to drug use within the first 2 years.

Figure 4 shows the average costs and effects of the six therapies. The $\mathrm{x}$-axis represents IPSS changes from the common baseline of 22; lower scores (greater change from baseline) indicate a better response after treatment. The most efficient treatments, those that result in the greater symptom relief for the money spent, are found along the production possibility frontier, the line connecting the southeastern most treatments. The least expensive and least effective treatment ComboRx (generic) is found in the southwest corner. Moving 
Table 2 Service components of BPH diagnosis, treatments for LUTS, and adverse events

\begin{tabular}{|c|c|c|c|}
\hline Service & Cost (US\$)/cycle & Included utilization & Reference \\
\hline Initiation of ComboRx & $\$ 519$ & OVs for diagnosis and titration & 62 \\
\hline therapy & & $\begin{array}{l}\text { Rx for } 2 \text { single-pill tamsulosin/Flomax, finasteride/Proscar }(90 \%) \text { or I } \\
\text { polytherapy dutasteride+tamsulosin/Jalyn ( } 10 \%) \text { pill }\end{array}$ & 63,64 \\
\hline \multirow[t]{2}{*}{ Ongoing ComboRx therapy } & $\$ 394$ & OVs for check-up (I visit annually) & 62 \\
\hline & & Rx for 2 single-pill (90\%) and I polytherapy (10\%) pill & 62 \\
\hline Rezūm ${ }^{\circledR}$ procedure and & $\$ 2,489$ & OVs for diagnosis, post-procedure assessment, and check-up (I visit annually) & 62 \\
\hline related & & Urodynamic study, cystoscopy, TRUS (50\%), and TUNA & 62 \\
\hline Prostiva ${ }^{\circledR}$ procedure and & $\$ 2,489$ & OVs for diagnosis, post-procedure assessment, and check-up (I visit annually) & 62 \\
\hline related & & Urodynamic study, cystoscopy, TRUS (50\%), and TUNA & 62 \\
\hline UroLift ${ }^{\circledR}$ procedure and & $\$ 6,230$ & OVs for diagnosis, post-procedure assessment, and check-up (I visit annually) & 62 \\
\hline related & & Urodynamic study, cystoscopy, TRUS (50\%), and PUL (4 implants) & 62 \\
\hline Greenlight ${ }^{\circledR}$ PVP procedure & $\$ 4,661$ & OVs for diagnosis, post-procedure assessment, and check-up (I visit annually) & 62 \\
\hline and related & & Urodynamic study, cystoscopy, TRUS (50\%), and PVP & 62 \\
\hline \multirow[t]{2}{*}{ TURP procedure and related } & $\$ 4,821$ & OVs for diagnosis, post-procedure assessment, and check-up (I visit annually) & 62 \\
\hline & & Urodynamic study, cystoscopy, TRUS (50\%), and TURP & 62 \\
\hline Dilation for stricture, & $\$ 665$ & OVs for diagnosis and post-procedure assessment & 62 \\
\hline contracture, or stenosis & & Cystoscopy, dilation (filaform or dilator), and radiological supervision & 62 \\
\hline Urethrotomy stricture, & $\$ 1,926$ & OVs for diagnosis and post-procedure assessment & 62 \\
\hline contracture, or stenosis & & Cystoscopy and urethrotomy & 62 \\
\hline TURBN for stricture, & $\$ 2,892$ & OVs for diagnosis and post-procedure assessment & 62 \\
\hline contracture, or stenosis & & Cystoscopy and TURBN & 62 \\
\hline Initiation of Rx therapy for & $\$ 155$ & OVs for diagnosis and titration & 62 \\
\hline erectile dysfunction & & Rx for erectile dysfunction (sildenafil), 2 pills per month & 63 \\
\hline Ongoing Rx therapy for & $\$ 31$ & OV for check-up (I annually) & 62 \\
\hline erectile dysfunction & & $\mathrm{Rx}$ for erectile dysfunction & 62 \\
\hline Initiation of injections for & $\$ 399$ & OVs for diagnosis and assessment & 62 \\
\hline erectile dysfunction & & Injections in-office & 62 \\
\hline Ongoing injections for & $\$ 66$ & OV for check-up (I annually) & 62 \\
\hline erectile dysfunction & & $\begin{array}{l}\text { Rx for self-injections ( } 33 \% \text { each branded Caverject, generic PEG-I, and } \\
\text { generic Tri-mix) }\end{array}$ & 65 \\
\hline Initiation of Rx therapy for & $\$ 579$ & OVs for diagnosis and titration & 62 \\
\hline incontinence & & $\begin{array}{l}\text { Rx for incontinence ( } 33 \% \text { each branded Vesicare, generic oxybutynin, and } \\
\text { generic tolterodine) }\end{array}$ & 66,67 \\
\hline Ongoing Rx therapy for & $\$ 454$ & OV for check-up (I annually) & 62 \\
\hline incontinence & & Rx for incontinence & 62 \\
\hline Initiation of PTNS therapy for & $\$ 2,007$ & OVs for diagnosis and 12 weekly treatments & 62 \\
\hline incontinence & & OVs monthly for maintenance therapy & 62 \\
\hline Ongoing PTNS therapy for & $\$ 795$ & OVs monthly for maintenance therapy & 62 \\
\hline incontinence & & OV for check-up (I annually) & 62 \\
\hline Initiation of Botox therapy & $\$ 1,798$ & OVs for diagnosis and assessment & 62 \\
\hline for incontinence & & Cystourethroscopy, with injection(s) for chemo-denervation & 62 \\
\hline \multirow[t]{2}{*}{ Ongoing Botox therapy } & $\$ 1,703$ & Injections for maintenance of chemo-denervation & 62 \\
\hline & & OV for check-up (I annually) & 62 \\
\hline AUS procedure for & $\$ 1,239$ & OVs for diagnosis and assessment & 62 \\
\hline incontinence & & Cystoscopy, urodynamic study, and AUS procedure & 62 \\
\hline \multirow[t]{2}{*}{ Rx for urinary tract infection } & $\$ 127$ & OV for diagnosis and check-up & 62 \\
\hline & & $\begin{array}{l}\text { Rx for urinary tract infection ( } 16 \% \text { each branded Monurol, generic } \\
\text { trimethoprim/sulfamethoxazole, nitrofurantoin, ciprofloxacin, levofloxacin, } \\
\text { and cephalexin) }\end{array}$ & $66-69$ \\
\hline Temporary therapy for acute & $\$ 145$ & OV for diagnosis & 62 \\
\hline urinary retention & & Cystoscopy and insertion of bladder catheter & 62 \\
\hline
\end{tabular}

Abbreviations: AUS, artificial urinary sphincter; BPH, benign prostatic hyperplasia; ComboRx, combination prescription drug therapy; Greenlight PVP (or PVP), photovaporization of the prostate; LUTS, lower urinary tract symptoms; OV, office visit; PEG-I, prostaglandin-I; Prostiva, conductive radiofrequency thermal therapy; PTNS, percutaneous tibial nerve stimulation; PUL (or UroLift), prostatic urethral lift; Rezūm, convective radiofrequency water vapor thermal therapy; Rx, prescription; Tri-mix, alprostadil, papaverine, and phentolamine; TRUS, transurethral ultrasound; TUNA, transurethral needle ablation; TURBN, transurethral resection of the bladder neck; TURP, transrectal resection of the prostate. 
Table 3 Costs, effectiveness, and ICERs of the treatments over a 2-year horizon

\begin{tabular}{|c|c|c|c|c|c|c|c|c|}
\hline \multirow[t]{2}{*}{ Attribute } & \multirow[t]{2}{*}{ Statistic } & \multicolumn{2}{|l|}{ ComboRx } & \multirow[t]{2}{*}{$\operatorname{Rezūm}^{\circledR}$} & \multirow[t]{2}{*}{ UroLift $^{\circledR}$} & \multirow[t]{2}{*}{ Prostiva $^{\circledR}$} & \multirow[t]{2}{*}{ Greenlight $^{\circledR}$} & \multirow[t]{2}{*}{ TURP } \\
\hline & & $\begin{array}{l}\text { Medicare } \\
\text { Part D price }\end{array}$ & $\begin{array}{l}\text { Branded } \\
\text { price }\end{array}$ & & & & & \\
\hline Cost & Mean at 2 years & $\$ 1,736$ & $\$ 7,082$ & $\$ 2,582$ & $\$ 6,386$ & $\$ 2,855$ & $\$ 5,099$ & $\$ 5,|8|$ \\
\hline IPSS & Mean at 2 years & 18.9 & 18.9 & 10.2 & II.4 & 10.9 & 7.4 & 6.4 \\
\hline Cost-effectiveness of & ICER at 2 years & $\$ 97$ & $-\$ 518$ & Base comparator & $-\$ 3,058$ & $-\$ 352$ & $\$ 900$ & $\$ 686$ \\
\hline Rezūm versus other ${ }^{\mathrm{a}}$ & Dominated & No & Yes & NA & Yes & Yes $^{b}$ & No & No \\
\hline Cost-effectiveness of & ICER at 2 years & $\$ 276$ & $-\$ 1,523$ & $\$ 6,863$ & $-\$ 240$ & $\$ 509$ & $\$ 83$ & Base comparator \\
\hline TURP versus other ${ }^{\mathrm{a}}$ & Dominated & No & Yes & No & Yes & No & No & NA \\
\hline
\end{tabular}

Notes: "Dominated" indicates a treatment that is more expensive and less effective than another is dominated by the other. ICER: cost per additional point reduction (in

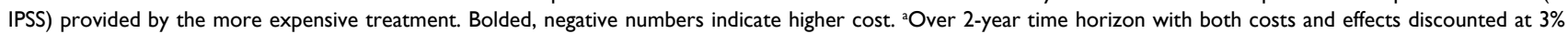
annually. ${ }^{\mathrm{b}}$ The mean IPSS and costs indicate dominance, but the effectiveness and costs are not dissimilar when uncertainty is considered. Costs based on US\$.

Abbreviations: ComboRx, combination prescription drug therapy; Greenlight PVP, photovaporization of the prostate; ICER, incremental cost-effectiveness ratio; IPSS, International Prostate Symptom Score; NA, not applicable; Prostiva, conductive radiofrequency thermal therapy; Rezūm, convective radiofrequency water vapor thermal therapy; TURP, transurethral resection of the prostate; UroLift, prostatic urethral lift.

north and east as costs and effects increase, Rezūm and Prostiva form the next frontier therapies. Greenlight PVP and TURP lie at the northeastern most point on the frontier as they are the most effective, but also the most costly.

The ICERs for ComboRx versus Rezūm and Rezūm versus TURP are represented by the slopes of the lines connecting generic ComboRx to Rezūm and Rezūm to TURP. The treatments along the curve connecting ComboRx (generic), Rezūm, and TURP are the most effective for the cost. Therapies that are inside this frontier are less effective and more costly (i.e., dominated by therapies on the frontier). (Note that there is an ICER for any two treatments, but only two of the ICERs, those on the production possibility frontier, are shown in Figure 4.)

\section{CEACs}

The CEACs shown in Figure 3 plot the probability that the more expensive therapy is cost-effective versus the maximum acceptable ICER. These plots summarize the probabilistic sensitivity analysis results shown in Figure 2. The comparisons include those therapies on the production possibility frontier: Rezūm versus generic ComboRx and TURP versus Rezūm. With the 1,000 simulated ICERs, Rezūm is always more expensive than generic ComboRx. Therefore, the $10 \%$ of ICERs that are negative is the result of instances in which ComboRx is more effective than Rezūm. The probabilistic sensitivity analysis indicates that $95 \%$ of the time, the cost per additional IPSS point reduction is less than $\$ 150$ over 2 years when Rezūm is used instead of ComboRx (Figure 3A). For $95 \%$ of the time, the cost per point reduction is less than $\$ 250$ over 2 years when TURP is used instead of Rezūm (Figure 3B).

\section{Discussion}

The cost-effectiveness analysis in this report is inclusive of a spectrum of therapies used for the management of LUTS/
BPH. It is important to understand the trends in utilization that impact the treatment patterns for BPH and the consequent cost-effectiveness. While medical therapy is a common first-line treatment option for mild-to-moderate voiding symptoms, TURP had been the main form of BPH surgical treatment for many years and remained a standard for improvements in urinary function to which other therapies were compared. Both pharmacological and technical interventions for BPH have continued to evolve as clinicians learn more about the disease. The thermal therapies (transurethral microwave thermotherapy [microwave-generated] and TUNA [RF-generated conductive heating; e.g., Prostiva]) and laser procedures (e.g., Greenlight PVP) as less morbid alternatives to TURP were associated with significant revival of interest in BPH interventions. Laser procedures have similar efficacy in symptom relief to TURP. As reported in several sources, the consequence of the newer therapeutic options was a steady decline in TURP procedures while laser vaporization increased steadily. ${ }^{69-71}$ PVP serves as an alternative to TURP as TURP may be associated with perioperative morbidities directly related to prostate volume and surgically high-risk patients with associated comorbidity, including pacemakers, and anticoagulant and platelet anti-aggregate medications. ${ }^{72,73}$ TURP and Greenlight PVP remain the most costly alternatives today and typically are reserved for treatment of moderate-to-severe LUTS or larger prostates. While they among the most cost-effective treatments for relief of symptoms as shown in Figure 4, the rates of AEs, including incontinence, UTI, ED, AUR, and bladder neck contracture, for these surgical procedures are significant, again contributing to more discomfort for the patients and costs to payers. ${ }^{74-76}$

The emergence of the newer MITs, first the UroLift as a permanent implant for mechanical lifting of prostate tissue (FDA clearance 2013), and the Rezūm System convective RF 

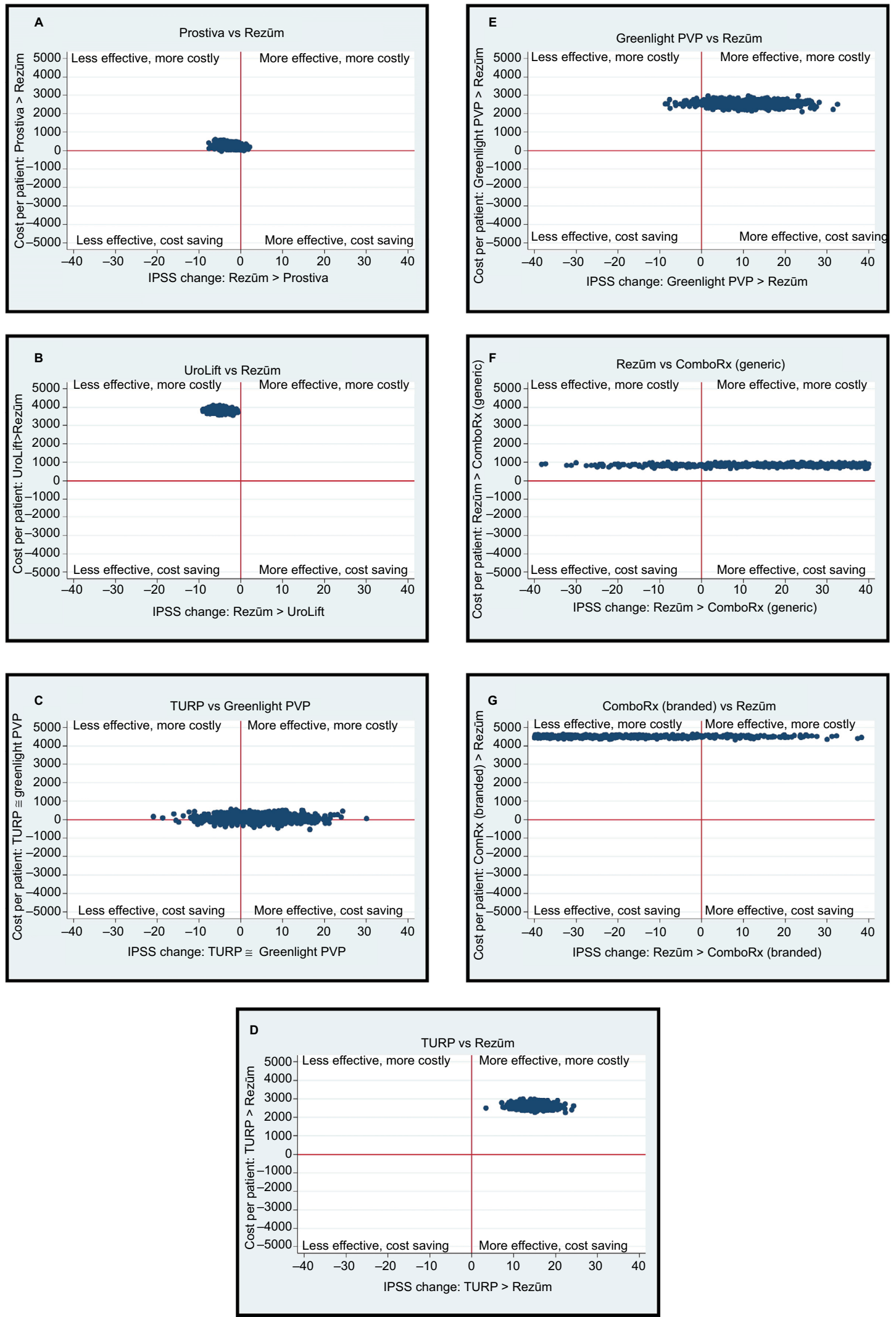

Figure 2 Cost-effectiveness simulations of minimally invasive and invasive therapies.

Notes: In 1000 simulated samples of size 100, these figures plot the differences in costs paired with the differences in effectiveness (improvements in IPSS) between two treatments. (A) Prostiva vs Rezūm, (B) UroLift vs Rezūm, (C) TURP vs Greenlight PVP, (D) TURP vs Rezūm, (E) Greenlight PVP vs Rezūm, (F) Rezūmvs ComboRx (generic), and (G) ComboRx (branded) vs Rezūm.

Abbreviations: ComboRx, combination prescription drug therapy; Greenlight ${ }^{\circledR}$ PVP, photovaporization of the prostate; IPSS, International Prostate Symptom Score; Prostiva $^{\circledR}$, conductive radiofrequency thermal therapy; Rezūm ${ }^{\circledast}$, convective radiofrequency water vapor thermal therapy; TURP, transurethral resection of the prostate; UroLift ${ }^{\circledR}$, prostatic urethral lift. 
A

Rezūm vs ComboRx (generic)

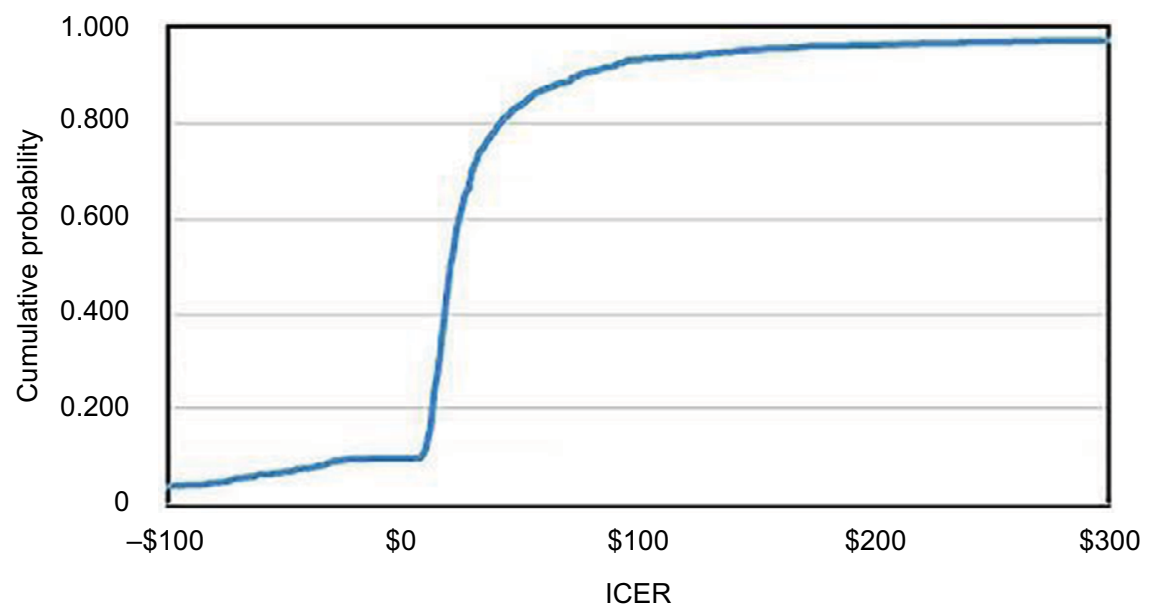

B

TURP vs Rezūm

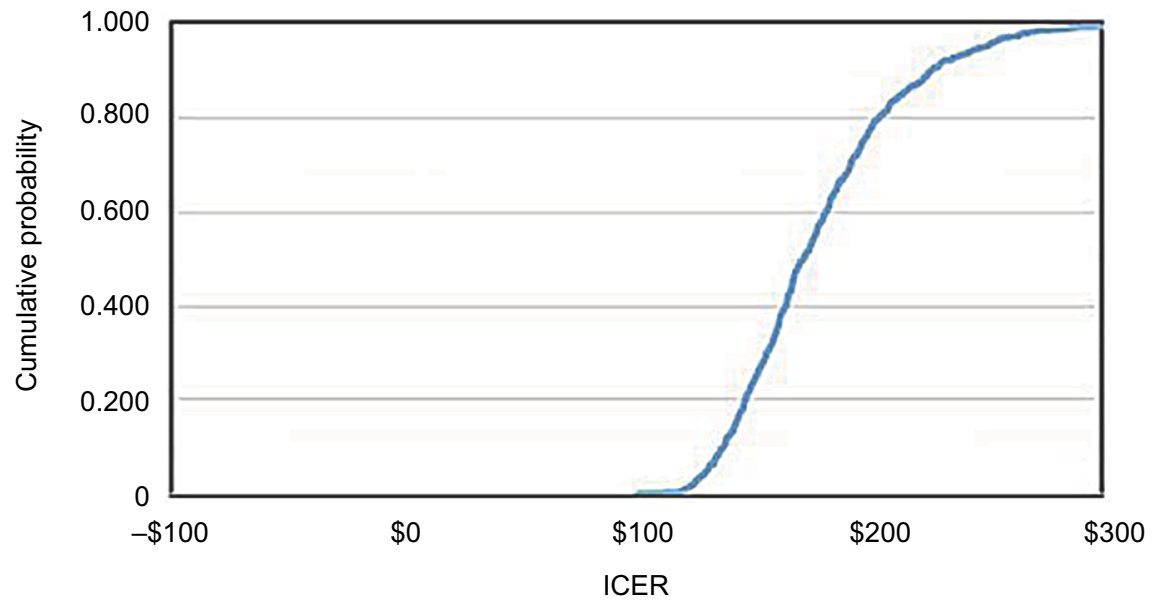

Figure 3 Cost-effectiveness (US\$) acceptability curves for (A) Rezūm ${ }^{\circledR}$ versus ComboRx and (B) TURP versus Rezūm. ICER: cost per additional point reduction (in IPSS) provided by the more expensive treatment.

Abbreviations: ComboRx, combination prescription drug therapy; ICER, incremental cost-effectiveness ratio; IPSS, International Prostate Symptom Score; Rezūm, convective radiofrequency water vapor thermal therapy; TURP, transurethral resection of the prostate.

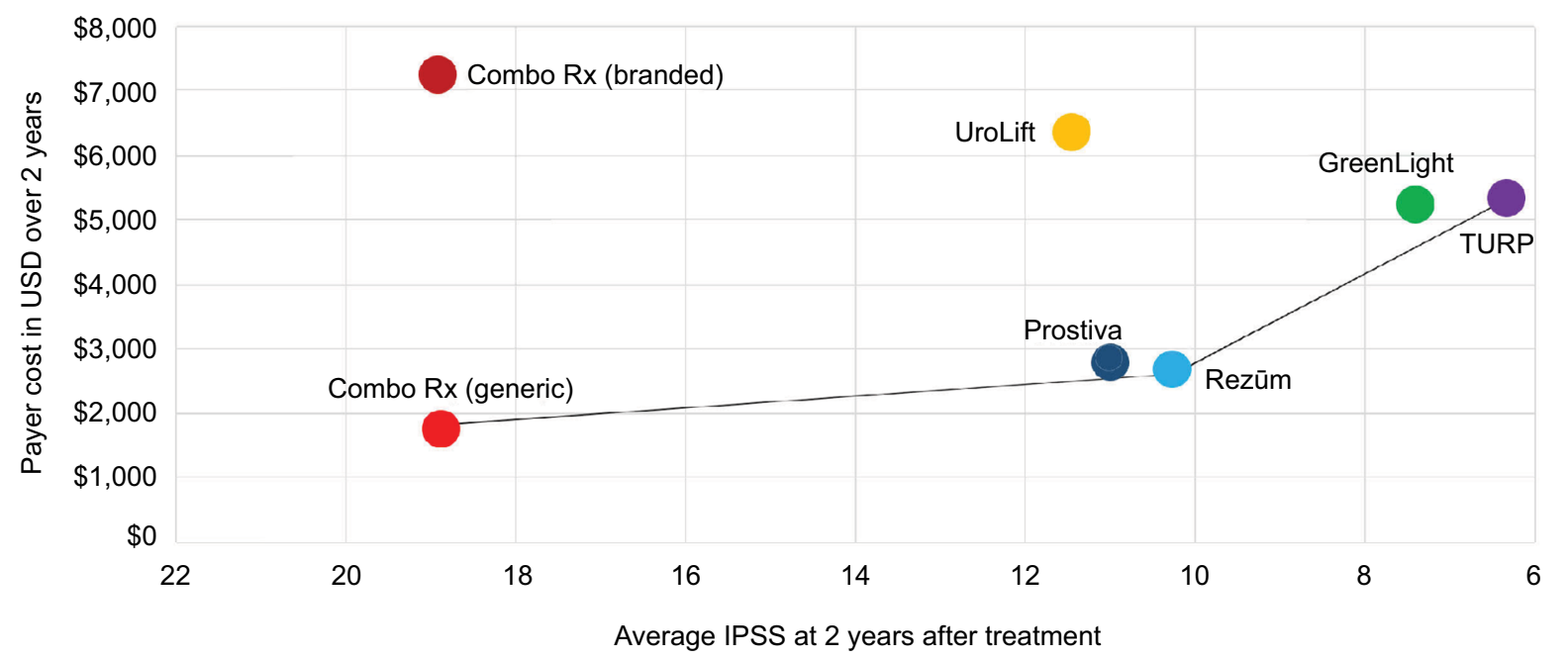

Figure 4 Production possibility frontier graph for average costs of the six therapies relative to cost-effectiveness over 2 years.

Note: The $x$-axis represents mean IPSS changes from the common baseline.

Abbreviations: ComboRx, combination prescription drug therapy; Greenlight ${ }^{\circledR}$ PVP, photovaporization of the prostate; IPSS, International Prostate Symptom Score; Prostiva $^{\circledR}$, conductive radiofrequency thermal therapy; Rezūm ${ }^{\circledR}$, convective radiofrequency water vapor thermal therapy; TURP, transurethral resection of the prostate; UroLift $^{\circledast}$, prostatic urethral lift. 
thermal therapy (FDA clearance 2015) that followed 2 years later, has given rise to therapies that provide durable relief of urinary symptoms over at least 2 years of follow-up with IPSS improvements nearly approaching those of TURP and Greenlight PVP for patients with moderate-to-severe LUTS/ $\mathrm{BPH}$. When the requirement for general anesthesia for Greenlight PVP and TURP is considered, the costs for these surgical procedures exclusive of the medical devices are higher than for either MIT. Both UroLift and Rezūm have been evaluated in rigorously controlled (sham procedure controls) clinical trials with strict inclusion and exclusion criteria performed by accomplished clinicians. The effectiveness of these two MITs is supported by selective evidence-based studies. Currently, these technologies serve as options in the continuum between medical management and surgical approaches due to demonstrated tolerability, safety and effectiveness, and cost savings. However, this study has shown that Rezūm is much less expensive and might be a preferred choice in a health care system seeking to contain costs.

The clinical reports for the earlier TUNA technology (Prostiva) predate 2003. This MIT has been evaluated in randomized comparative studies versus TURP in 25-65 patients, although not in sham-controlled studies. ${ }^{34,55,77}$ Traditional RF thermotherapy with a TUNA system, the Prostiva system, has had little change in utilization from 2000 to 2008 possibly as a consequence of being overshadowed by aggressive marketing of laser vaporization. ${ }^{70}$ The Rezūm System utilizes the convective delivery of stored thermal energy via steam water vapor created with RF electromagnetic energy, rather than the application of RF energy directly to prostate tissue with the Prostiva System which relies on the conductive delivery of heat thermal energy through the tissue. Thus, ablative RF thermal energy convectively delivered with the Rezūm System is confined within the prostatic capsule and prevents the conduction of harmful levels of electromagnetic energy outside the intended treatment areas, which could result in collateral tissue damage. The convective delivery of "wet" RF thermal energy into the prostate by the Rezūm System preserves the prostatic urethra, while also avoiding adverse clinical effects such as tissue carbonization, charring, or tissue desiccation that can result from the application of RF energy directly to prostate tissue as with the Prostiva System. ${ }^{78}$

The production possibility frontier is anchored by TURP/ Greenlight PVP and pharmaceuticals that have been available for years (Figure 4). The UroLift procedure falls between the two anchors, but the newly established reimbursement framework has pulled the cost-effectiveness line substantially northward for this MIT leaving Prostiva and Rezūm as therapeutic options at a lower cost and with a similar effectiveness (Table 1). The ICER for UroLift versus Rezūm is negative (approximately $-\$ 3,000$ ) because UroLift costs more and provides slightly less relief than Rezūm (although not a clinically significant amount) for each incremental improvement in urinary symptom relief compared with Rezūm. Thus, the model estimates that on average Rezūm ranks favorably among the MITs; UroLift is the most expensive. Rezūm has been shown to provide consistent and durable improvements in LUTS throughout 2 years of follow-up,,$^{26,78,79}$ and has a substantially lower rate for return of symptoms (Table 1). The re-treatment rate for Rezūm is about $4 \%$ over 2 years ${ }^{26}$ compared with about $7.5 \%$ for UroLift. ${ }^{28}$

Evaluation of ComboRx on the production possibility frontier (Figure 4) and ICERs (Table 3) shows a therapy that is the most expensive for branded drugs, least expensive for generic drugs, and the least effective for both generic and branded ComboRx. Medications for treatment of BPH do not provide immediate gratification for the patients as they may take up to 2 years of continuous use to obtain maximum benefit. Furthermore, whether due to AEs or dissatisfaction with medications, patients often interrupt therapy - stopping and restarting, changing prescriptions, or discontinuing completely. ${ }^{14,80}$ The rate of discontinuation after 12 months of medication therapy ranges from 62 to $91 \% .^{14,80,81}$

As shown in clinical studies evaluated in this report, the maximum urinary symptom relief attained with ComboRx is only about $50 \%$ as effective as any MIT procedure; in this study, they were about one-third as effective. Thus, there is a good argument to be made that given the substantial costeffectiveness evidence of MITs to treat LUTS/BPH, MITs could be considered as the first line of treatment compared to the low effectiveness of generic and branded agents in place of ComboRx if the 2-year results continue over 4 or more years. The additional 2-year costs would be justified based on the higher effectiveness, and over as little as 4 years, the total costs of ComboRx may exceed those of the MITs. Among the MITs, the Rezūm System warrants consideration as a firstline treatment choice for the earlier management of LUTS/ $\mathrm{BPH}$. It has both a favorable cost-effectiveness and excellent safety/tolerability profile relative to UroLift and Prostiva, and circumvents the need for long-term use. It does not have the unpredictability of outcomes associated with ComboRx. As value- and quality-based payment programs continue to evolve, technologies that demonstrate cost-effectiveness and provide good outcomes will continue to move to the forefront and provide benefit to physicians and patients. ${ }^{82}$ 
The authors recognize several limitations of the study. BPH and associated LUTS is a condition affecting quality of life with varying incidence and degrees of severity among the spectrum of the seven typical symptoms compounded by the dynamics of aging in the patient. Thus, the analysis is not confined to a hypothetical patient with LUTS/BPH from whom we can draw overall conclusions. Rather, the sample of patients assessed is heterogeneous; the analysis represents the continuum of care that a patient may experience based on variables such as degree of symptom bother, tolerance, prostate size or comorbidities, and therapeutics available to them. We have utilized the treatment experiences of published reports realizing that clinical outcomes for the new MIT procedures have been derived from smaller numbers of patients and shorter durations of follow-up evaluations. This is in contrast to follow-up for large numbers of patients receiving drug therapy and invasive surgical procedures, which have been in use as treatment options for over a decade.

\section{Conclusion}

This cost-effectiveness analysis of the treatment options for the disease pathway of the severities of LUTS due to BPH was conducted in the context of currently available therapeutic options. On one end of the spectrum are generic ComboRx medications, the typical initial treatment option for bothersome LUTS. The medication option is the least expensive but not cost-effective as this modality requires extended use to barely achieve half the urinary symptom improvements obtained through minimally invasive procedures. At the other end of the spectrum, a surgical intervention such as TURP has the highest procedural cost but requires more stringent criteria for use. TURP is typically reserved for patients with obstructive prostatic hypertrophy in whom medical management and less-invasive prostatic surgical procedures have failed, or who have large prostates or an unusual shape that could include an enlarged median lobe or significant intravesical prostatic encroachment. Both Greenlight PVP and TURP provide similar and greater symptom relief; however, these options also demonstrate higher rates of AEs and increased procedure time, and potentially require general/ spinal anesthesia, adding additional costs to the payer. The MITs including the two RF thermal therapies Prostiva and Rezūm, and the UroLift procedure may be viewed as intermediate interventions and more effective than medications for BPH, although not as effective as TURP or PVP. They can be performed as outpatient or same-day procedures and are less costly overall. UroLift was the most expensive of the MITs. Evidence-based evaluations support Rezūm as a cost- and clinically effective treatment for BPH, given the urinary symptom score improvements, markedly improved from baseline and throughout 2 years, and minimal transient perioperative side effects. As such, Rezūm warrants consideration as a first-line therapeutic alternative to medical therapy in men seeking treatment for bothersome moderate-to-severe symptoms of BPH, including those with median lobe hyperplasia. Evaluation of the cost-effectiveness of treatments of LUTS/BPH that improve patients' quality of life is both relevant to clinicians seeking expedient and cost-conscious therapies and to payers' reimbursement plans driven (or necessitated) by value-based medical care.

\section{Acknowledgments}

This study was supported by NxThera, Inc., Maple Grove, MN, USA. The study results have not been contingent on the sponsor's approval nor has the sponsor been involved in censorship of the report.

\section{Disclosure}

Dr. Ulchaker participated as a clinical investigator in the pivotal trial of the convective RF water vapor thermal therapy. Dr. Martinson of Technomics Research was contracted to perform the cost-effectiveness analysis. The authors report no other conflicts of interest in this work.

\section{References}

1. Fenter TC, Naslund MJ, Shah MB, Eaddy MT, Black L. The cost of treating the 10 most prevalent diseases in men 50 years of age or older. Am J Manag Care. 2006;12(4 Suppl):S90-S98.

2. Welch G, Weinger K, Barry MJ. Quality-of-life impact of lower urinary tract symptom severity: results from the Health Professionals Follow-up Study. Urology. 2002;59(2):245-250.

3. Rosen R, Altwein J, Boyle P, et al. Lower urinary tract symptoms and male sexual dysfunction: the multinational survey of the aging male (MSAM-7). Eur Urol. 2003;44(6):637-649.

4. Hollingsworth JM, Wei JT. Economic impact of surgical intervention in the treatment of benign prostatic hyperplasia. Rev Urol. 2006;8(Suppl 3):S9-S15.

5. Isaacs JT, Coffey DS. Etiology and disease process of benign prostatic hyperplasia. Prostate Suppl. 1989;2(Suppl):33-50.

6. Barry MJ. Epidemiology and natural history of benign prostatic hyperplasia. Urol Clin North Am. 1990;17(3):495-507.

7. American Urological Association guideline: management of benign prostatic hyperplasia (BPH). 2010. Available from: http://www.auanet.org/common/pdf/education/clinical-guidance/Benign-ProstaticHyperplasia.pdf. Accessed July 13, 2017.

8. Wei JT, Calhoun E, Jacobsen SJ. Urologic diseases in America project: benign prostatic hyperplasia. J Urol. 2005;173(4):1256-1261.

9. Platz EA, Joshu CE, Mondul AM, Peskoe SB, Willett WC, Giovannucci E. Incidence and progression of lower urinary tract symptoms in a large prospective cohort of United States men. J Urol. 2012;188(2):496-501.

10. Amerson D. UroLift for BPH: changing the game in BPH care. Paper presented at: AACU State Advocacy Conference; September 18-19, 2015; Chicago, IL.

11. Vuichoud C, Loughlin KR. Benign prostatic hyperplasia: epidemiology, economics and evaluation. Can J Urol. 2015;22 Suppl 1:1-6. 
12. Saigal CS, Joyce G. Economic costs of benign prostatic hyperplasia in the private sector. $J$ Urol. 2005;173(4):1309-1313.

13. Koh JS, Cho KJ, Kim HS, Kim JC. Twelve-month medication persistence in men with lower urinary tract symptoms suggestive of benign prostatic hyperplasia. Int J Clin Pract. 2014;68(2):197-202.

14. Cindolo L, Pirozzi L, Fanizza C, et al: Drug adherence and clinical outcomes for patients under pharmacological therapy for lower urinary tract symptoms related to benign prostatic hyperplasia: population-based cohort study. Eur Urol. 2015;68(3):418-425.

15. Nichol MB, Knight TK, Wu J, Barron R, Penson DF. Evaluating use patterns of and adherence to medications for benign prostatic hyperplasia. J Urol. 2009;181(5):2214-2221.

16. Kaplan S, Naslund M. Public, patient, and professional attitudes towards the diagnosis and treatment of enlarged prostate: a landmark national US survey. Int J Clin Pract. 2006;60(10):1157-1165.

17. Emberton M, Marberger M, de la Rosette J. Understanding patient and physician perceptions of benign prostatic hyperplasia in Europe: the Prostate Research on Behaviour and Education (PROBE) Survey. Int J Clin Pract. 2008;62(1):18-26.

18. Centers for Disease Control and Prevention. Public health and aging: trends in aging - United States and worldwide. JAMA. 2003;289(11): 1371-1373.

19. European Association of Urology. Guidelines on the management of non-neurogenic male lower urinary tract symptoms (LUTS) including benign prostatic obstruction (BPO). 2015. Available from: http://uroweb. org/wp-content/uploads/EAU-Guidelines-Non-Neurogenic-MaleLUTS-Guidelines-2015-v2.pdf. Accessed July 13, 2017.

20. Mullins C, Kaplan SA. A new vision for the study of benign prostate disease: the NIDDK Prostate Research Strategic Plan. $J$ Urol. 2009;181(3):963-971.

21. U.S. Department of Health and Human Services, Center for Medicare and Medicaid Services. 2016. MedPAR LDS - Hospital (National) FY2016 MedPAR LDS [Data Set]. Available from: https://www.cms gov/Research-Statistics-Data-and-Systems/Files-for-Order/LimitedDataSets/MEDPARLDSHospitalNational.html. Accessed June 23, 2016.

22. McConnell JD, Roehrborn CG, Bautista OM, et al; Medical Therapy of Prostatic Symptoms (MTOPS) Research Group. The long-term effect of doxazosin, finasteride, and combo therapy on the clinical progression of benign prostatic hyperplasia. N Engl J Med. 2003;349(25):2387-2398.

23. Roehrborn CG, Siami P, Barkin J, et al; CombAT Study Group. The effects of combination therapy with dutasteride and tamsulosin on clinical outcomes in men with symptomatic benign prostatic hyperplasia: 4-year results from the CombAT study. Eur Urol. 2010;57(1):123-131.

24. McVary KT, Gange SN, Gittelman MC, et al. Minimally invasive prostate convective water vapor energy (WAVE) ablation: a multicenter, randomized, controlled study for treatment of lower urinary tract symptoms secondary to benign prostatic hyperplasia. J Urol. 2015;195:1529-1538.

25. McVary KT, Gange SN, Gittelman MC, et al. Erectile and ejaculatory function preserved with convective water vapor energy treatment of lower urinary tract symptoms secondary to benign prostatic hyperplasia: randomized controlled study. J Sex Med. 2016;13(6):924-933.

26. Roehrborn CG, Gange SN, Gittelman MC, et al. Convective water vapor energy ablation therapy: durable two-year results and prospective blinded crossover study for treatment of lower urinary tract symptoms due to benign prostatic hyperplasia. J Urol. 2017;197(6):1507-1516.

27. Woo HH, Chin P, McNicholas TA, et al. Safety and feasibility of the prostatic urethral lift: a novel, minimally invasive treatment for lower urinary tract symptoms (LUTS) secondary to benign prostatic hyperplasia (BPH). BJU Int. 2011;108(1):82-88.

28. Roehrborn CG, Gange SN, Shore ND, et al. Durability of the prostate urethral lift: 2-year results of the LIFT Study. Urol Pract. 2015;2(1):26-32.

29. McNicholas TA, Woo HH, Chin PT, et al. Minimally invasive prostatic urethral life: surgical technique and multinational experience. Eur Urol. 2013;64(2):292-299.
30. McVary KT, Gange SN, Shore ND, et al. Treatment of LUTS secondary to BPH while preserving sexual function: randomized controlled study of prostatic urethral lift. J Sex Med. 2014;11(1):279-287.

31. Cantwell AL, Bogache WK, Richardson SF, et al. Multicentre prospective crossover study of the "prostatic urethral lift" for the treatment of lower urinary tract symptoms secondary to benign prostatic hyperplasia. BJU Int. 2014;113(4):615-622.

32. Roehrborn CG, Rukstalis DB, Barkin J, et al. Three year results of the prostatic urethral L.I.F.T. study. Can J Urol. 2015;22(3):7772-7782.

33. Sønksen J, Barber NJ, Speakman MJ, et al. Prospective, randomized, multinational study of prostatic urethral lift versus transurethral resection of the prostate: 12-month results of the BPH6 study. Eur Urol. 2015;68(4):643-652.

34. Hindley RG, Mostafid AH, Brierly RD, Harrison NW, Thomas PJ, Fletcher MS. The 2-year symptomatic and urodynamic results of a prospective randomized trial of interstitial radiofrequency therapy vs transurethral resection of the prostate. BJU Int. 2001;88(3):217-220.

35. Murai M, Tachibana M, Miki M, Shiozawa H, Hirao Y, Okajima E. Transurethral needle ablation of the prostate: an initial Japanese clinical trial. Int J Urol. 2001;8(3):99-105.

36. Daehlin L, Gustavsen A, Nilsen AH, Mohn J. Transurethral needle ablation for the treatment of lower urinary tract symptoms associated with benign prostatic hyperplasia: outcome after 1 year.J Endourol. 2002;16(2):111-115.

37. Zlotta AR, Giannakopoulos X, Maehum O, Ostrem T, Schulman CC. Long-term evaluation of transurethral needle ablation of the prostate (TUNA) for treatment of symptomatic benign prostatic hyperplasia: clinical outcome up to five years from three centers. Eur Urol. 2003;44(1):89-93.

38. Hill B, Belville W, Bruskewitz R, et al. Transurethral needle ablation versus transurethral resection of the prostate for the treatment of symptomatic benign prostatic hyperplasia: 5-year results of a prospective, randomized, multicenter clinical trial. JUrol. 2004;171(6 Pt 1):2336-2340.

39. Kim TS, Choi S, Rhew HY, et al. Comparative study on the treatment outcome and safety of TURP, ILC, TUNA and TEAP for patients with benign prostatic hyperplasia. Korean J Urol. 2006;4:13-9.

40. Ohigashi T, Nakamura K, Nakashima J, Baba S, Murai M. Long-term results of three different minimally invasive therapies for lower urinary tract symptoms due to benign prostatic hyperplasia: comparison at a single institute. Int J Urol. 2007;14(4):326-330.

41. Rosario DJ, Phillips JT, Chapple CR. Durability and cost-effectiveness of transurethral needle ablation of the prostate as an alternative to transurethral resection of the prostate when alpha-adrenergic antagonist therapy fails. $J$ Urol. 2007;177(3):1047-1051.

42. Malek RS, Kuntzman RS, Barrett DM. Photoselective potassium-titanylphosphate laser vaporization of the benign obstructive prostate: observations on long-term outcomes. $J$ Urol. 2005;174(4 Pt 1):1344-1348.

43. Sarica K, Alkan E, Luleci H, Tasci I. Photoselective vaporization of the enlarged prostate with KTP laser: long-term results in 240 patients. J Endourol. 2005;19(10):1199-1202.

44. Alivizatos G, Skolarikos A, Chalikopoulos D, et al. Transurethral photoselective vaporization prostatectomy versus transvesical open enucleation for prostatic adenomas $>80 \mathrm{ml}: 12$-mo results of a randomized prospective study. Eur Urol. 2008;54(2):427-437.

45. Spaliviero M, Araki M, Wong C. Short-term outcomes of Greenlight HPS laser photoselective vaporization prostatectomy (PVP) for benign prostatic hyperplasia (BPH). J Endourol. 2008;22(10):2341-2347.

46. Bouchier-Hayes DM, Van Appledorn S, Bugeja P, Crowe H, Challacombe B, Costello AJ. A randomized trial of photoselective vaporization of the prostate using the $80-\mathrm{W}$ potassium-titanyl-phosphate laser vs transurethral prostatectomy with a 1-year follow-up. BJU Int. 2009;105(7):964-969.

47. Ruszat R, Seitz M, Wyler S, et al. Prospective single-centre comparison of the 120-W diode pumped solid-state high-intensity system laser vaporization of the prostate and $200-\mathrm{W}$ high-intensive diode-laser ablation of the prostate for treating benign prostatic hyperplasia. $B J U$ Int. 2009;104(6):820-825. 
48. Spaliviero M, Araki M, Culkin D. Incidence, management, and prevention of perioperative complication of GreenLight HPS laser PVP: experience in first 70 patients. $J$ Endourol. 2009;23:495-502.

49. Al-Ansari A, Younes N, Sampige V, et al. GreenLight HPS 120-W laser vaporization versus transurethral resection of the prostate for the treatment of benign prostatic hyperplasia: a randomized clinical trial with midterm follow-up. Eur Urol. 2010;58(3):349-355.

50. Bachmann A, Tubaro A, Barber N, et al. 80-W XPS Greenlight laser vaporisation versus transurethral resection of the prostate for the treatment of benign prostatic hyperplasia: 6-month safety and efficacy results of a European multicentre randomised trial - the GOLIATH study. Eur Urol. 2014;65(5):931-942.

51. Bachmann A, Tuberos A, Barger N, et al. European multicenter randomized no inferiority trial comparing $180 \mathrm{~W}$ Greenlight XPS laser vaporization and transurethral resection of the prostate for the treatment of benign prostatic obstruction: 12-month results of the GOLIATH study. J Urol. 2015;93:570-578.

52. de la Rosette J, Elhilali M, Naito S, et al. Clinical Research Office of the Endourological Society Global GreenLight Laser Study: outcomes from a contemporary series of 713 patients. Int $J$ Urol. 2015;22(12):1124-1130.

53. Hueber P, Bienz M, Valdivieso R, et al. Photoselective vaporization of the prostate for benign prostatic hyperplasia using the 180 Watt system: multicenter study of the impact of prostate size on safety and outcomes. J Urol. 2015;194(2):462-469.

54. Thomas J, Tubaro A, Barber N, et al. A multicenter randomized noninferiority trial comparing greenlight-XPS laser vaporization of the prostate and transurethral resection of the prostate for the treatment of benign prostatic hyperplasia: two-year year outcomes of the GOLIATH study. Eur Urol. 2016;69:94-102.

55. Cimentepe E, Unsal A, Saglam R. Randomized clinical trial comparing transurethral needle ablation with transurethral resection of the prostate for the treatment of benign prostatic hyperplasia: results at 18 months. $J$ Endourol. 2003;17(2):103-107.

56. Mattiasson A, Wagrell L, Schelin S, et al. Five-year follow-up of feedback microwave thermotherapy versus TURP for clinical BPH: a prospective randomized multicenter study. Urology. 2007;69(1):91-96.

57. Seckiner I, Yessili C, Akduman B, Altan K, Mungan NA. A prospective randomized study for comparing bipolar plasmakinetic resection of the prostate with standard TURP. Urol Int. 2006;76(2):139-143.

58. Xia SJ, Zhuo J, Sun XW, Han BM, Shao Y, Zhang YN. Thulium laser versus standard transurethral resection of the prostate: a randomized prospective trial. Eur Urol. 2008;53(2):382-390.

59. Kaplan S, Lee J, Meehan J, et al. Time course of incident adverse experiences associated with doxazosin, finasteride, and combo therapy in men with BPH: the medical therapy of prostatic symptoms (MTOPS) trial. J Urol. 2016;195:1825-1829.

60. Fu WJ, Hong BF, Yang Y, et al. Photoselective vaporization of the prostate in the treatment of benign prostatic hyperplasia. Chin Med J (Engl). 2005;118(19):1610-1614.

61. Nørby B, Nielsen HV, Frimody-Møller PC. Transurethral interstitial laser coagulation of the prostate and transurethral microwave thermotherapy vs transurethral resection or incision of the prostate: results of a randomized, controlled study in patients with symptomatic benign prostatic hyperplasia. BJU Int. 2002;90(9):853-862.

62. U.S. Department of Health and Human Services, Center for Medicare and Medicaid Services. 2016. Part B National Summary Data File. [Data Set]. Available from: https://www.cms.gov/Research-Statistics-Dataand-Systems/Downloadable-Public-Use-Files/Part-B-National-Summary-Data-File/Overview.html. Accessed June 23, 2016.

63. U.S. Department of Health and Human Services, Center for Medicare and Medicaid Services. (2014). Part D Part D Prescriber Data CY2014. [Data Set]. Available from https://www.cms.gov/ResearchStatistics-Data-and-Systems/Statistics-Trends-and-Reports/MedicareProvider-Charge-Data/PartD2014.html. Accessed October 25, 2016.

64. Drugs.com. Available from: www.drugs.com. Accessed October 15, 2016.
65. Medscape.com. Available from: www.medscape.com. Accessed October $15,2016$.

66. U.S. Department of Health and Human Services, Center for Medicare and Medicaid Services. 2014. Part D Part D Prescriber Data CY2014. [Data Set]. Available from: https://www.medicaid.gov/medicaid/ prescription-drugs/pharmacy-pricing/index.html. Accessed November $2,2016$.

67. Walgreens.com. Available from: www.walgreens.com. Accessed October 16, 2016.

68. Walmart.com. Available from: www.walmart.com. Accessed October $16,2016$.

69. Yu X, Elliott SP, Wilt TJ, McBean AM. Practice patterns in benign prostatic hyperplasia surgical therapy: the dramatic increase in minimally invasive technologies. J Urol. 2008;180(1):241-245.

70. Malaeb BS, Yu X, McBean AM, Elliott SP. National trends in surgical therapy for benign prostatic hyperplasia in the United States (2000 2008). Urology. 2012;79(5):1111-1116.

71. Table 2-18. Benign prostatic hyperplasia, lower urinary tract symptoms, bladder stones. In: Litwin MS, Saigal CS, editors. Urologic diseases in America. US Department of Health and Human Services, Public Health Service, National Institutes of Health, National Institute of Diabetes and Digestive and Kidney Diseases. NIH Publication No. 12-7865. Washington, DC: US Government Printing Office; 2012:62. Available from: https://www.niddk.nih.gov/about-niddk/strategic-plans-reports. Accessed December 15, 2017.

72. Thomas JA, Tubaro A, Barber N, et al. The continuing story of the cost-effectiveness of photoselective vaporization of the prostate versus transurethral resection of the prostate for the treatment of symptomatic benign prostatic obstruction. Value Health. 2015;18(4):376-386.

73. Elhilali MM, Elkoushy MA. Greenlight laser vaporization versus transurethral resection of the prostate for the treatment of benign prostatic obstruction: evidence from randomized controlled studies. Transl Androl Urol. 2016;5(3):388-392.

74. Mamoulakis C, Efthimiou I, Kazoulis S, Christoulakis I, Sofras F. The modified Clavien classification system: a standardized platform for reporting complications in transurethral resection of the prostate. World J Urol. 2011;29(2):205-210.

75. Reich O, Gratzke C, Bachmann A, et al. Morbidity, mortality and early outcome of transurethral resection of the prostate: a prospective multicenter evaluation of 10,654 patients. J Urol. 2012;180(1):246-249.

76. Omar MI, Lam TB, Alexander CE, et al. Systematic review and meta-analysis of the clinical effectiveness of bipolar compared with monopolar transurethral resection of the prostate (TURP). BJU Int. 2014;113(1):24-35.

77. Roehrborn CG, Burkhard FC, Bruskewitz RC, et al. The effects of transurethral needle ablation and resection of the prostate on pressure flow urodynamic parameters: analysis of the United States randomized study. J Urol. 1999;162(1):92-97.

78. Woo HH, Gonzalez RR. Perspective on the Rezūm ${ }^{\circledR}$ system: a minimally invasive treatment strategy for benign prostatic hyperplasia using convective radiofrequency water vapor thermal therapy. Med Devices (Auckl). 2017;10:71-80.

79. Dixon CM, Cedano ER, Pacik D, et al. Two-year results after convective water vapor energy treatment of symptomatic benign prostatic hyperplasia. Res Rep Urol. 2016;8:207-116.

80. Verhamme KM, Dieleman JP, Bleumink GS, Bosch JL, Stricker BH, Sturkenboom MC. Treatment strategies, patterns of drug use and treatment discontinuation in men with LUTS suggestive of benign prostatic hyperplasia: the Triumph Project. Eur Urol. 2003;44(5):539-545.

81. Issa MM, Lin PJ, Eaddy MT, Shah MB, Davis EA. Comparative analysis of alpha-blocker utilization in combination with 5-alpha reductase inhibitors for enlarged prostate in a managed care setting among Medicareaged men. Am J Manag Care. 2008;14(5 Suppl 2):S160-S166.

82. Quality Payment Program. United States Department of Health and Human Services. Available from: https://qpp.cms.gov/. Accessed August 4, 2016. 
ClinicoEconomics and Outcomes Research is an international, peerreviewed open-access journal focusing on health technology assessment, pharmacoeconomics and outcomes research in the areas of diagnosis, medical devices, and clinical, surgical and pharmacological intervention. The economic impact of health policy and health systems organization also constitute important areas of coverage. The manuscript management system is completely online and includes a very quick and fair peer-review system, which is all easy to use. Visit http://www.dovepress.com/testimonials.php to read real quotes from published authors.

Submit your manuscript here: https://www.dovepress.com/clinicoeconomics-and-outcomes-research-journal 